\title{
Health status, quality of life and medical care in adult women with Turner syndrome
}

\author{
Diana-Alexandra ErtI ${ }^{1}$, Andreas Gleiss' ${ }^{2}$, Katharina Schubert ${ }^{1}$, Caroline Culen ${ }^{1}$, Peer Hauck ${ }^{3}$, Johannes Ott ${ }^{4}$, \\ Alois Gess| ${ }^{5}$ and Gabriele Haeusler ${ }^{1}$ \\ 'Department of Pulmonology, Allergology and Endocrinology, University Clinic for Pediatrics and Adolescent Medicine, Medical University of Vienna, \\ Vienna, Austria \\ ${ }^{2}$ Center for Medical Statistics, Informatics, and Intelligent Systems, Medical University of Vienna, Vienna, Austria \\ ${ }^{3}$ Pediatric Heart Center Vienna, University Clinic for Pediatrics and Adolescent Medicine, Medical University of Vienna, Vienna, Austria \\ ${ }^{4}$ Clinic Division for Gynecologic Endocrinology and Reproductive Medicine, Medical University of Vienna, Vienna, Austria \\ ${ }^{5}$ Division of Endocrinology, University Clinic of Internal Medicine III, Medical University of Vienna, Vienna, Austria
}

Correspondence should be addressed to G Haeusler: gabriele.haeusler@meduniwien.ac.at

\begin{abstract}
Background: Previous studies have shown that only a minority of patients with Turner syndrome (TS) have adequate medical care after transfer to adult care.

Aim of this study: To assess the status of medical follow-up and quality of life (QoL) in adult women diagnosed with TS and followed up until transfer. To compare the subjective and objective view of the medical care quality and initiate improvements based on patients' experiences and current recommendations.

Methods: 39 adult women with TS out of 64 patients contacted were seen for a clinical and laboratory check, cardiac ultrasound, standardized and structured questionnaires (SF-36v2 and Beck depression inventory).

Results: 7/39 of the patients were not being followed medically at all. Only 2/39 consulted all the specialists recommended. Comorbidities were newly diagnosed in 27/39 patients; of these, 11 related to the cardiovascular system. Patients in our cohort scored as high as the mean reference population for SF-36v2 in both mental and physical compartments. Obese participants had lower scores in the physical function section, whereas higher education was related to higher physical QoL scores. Adult height slightly correlated positively with physical health.

Conclusion: Medical follow-up was inadequate in our study cohort of adults with TS. Even though their medical follow-up was insufficient, these women felt adequately treated, leaving them vulnerable for premature illness. Initiatives in health autonomy and a structured transfer process as well as closer collaborations within specialities are urgently needed.
\end{abstract}

\author{
Key Words \\ - Turner syndrome \\ - quality of life \\ - health status \\ - health care \\ - follow-up \\ comorbidities
}

\section{Introduction}

Morbidity and mortality are generally increased in Turner syndrome (TS) (1). Therefore, extensive guidelines for the health care of young and adult patients with TS have been published $(2,3,4,5,6,7,8)$, with a special focus on screening and follow-up for cardiovascular disorders $(9,10)$. However, several studies have shown that only a minority of adult TS patients have adequate medical follow-up after transition to adult care $(11,12,13)$ and that a considerable proportion of the women with induced puberty no longer had any estrogen therapy (14).

The reasons for insufficient medical care for women with TS in adulthood may be manifold. Transfer from pediatric to adult medical care is a challenge for both patients and the health care system for many chronic http://www.endocrineconnections.org https://doi.org/10.1530/EC-18-0053 (c) 2018 The authors Published by Bioscientifica Ltd

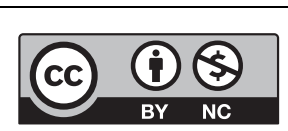

This work is licensed under a Creative Commons Attribution-NonCommercial 4.0 International License. 
conditions (15). Transition is particularly difficult for young adults with TS, as they are usually diagnosed by pediatric endocrinologists or cardiologists due to their clinical manifestation with growth and puberty disorders or congenital heart disease. Difficulty arises once the focus of health care changes with age and as the adult care setting is currently poorly adjusted for multidisciplinary follow-up of rare disorders in many institutions throughout the world (16). On the other hand, it has been suggested that young women with TS are often not fully aware of their condition. A specific neurocognitive phenotype and lack of social skills, as well as impaired executive functions have been described $(17,18,19,20,21)$. A combination of these institutional and disorder-specific issues may be the reason for suboptimal medical care in adult women with TS despite published recommendations.

The aim of this study was thus to assess the subjective and objective quality of current medical care of adult patients with TS, who had been under the care of our pediatric department, to screen for comorbidities and to evaluate their quality of life (QoL). We combined standardized questionnaires with appointments, investigations and explorative interviews and offered suggestions for improvements directly to our former patients.

\section{Methods}

\section{Participants and recruitment}

The study involved adult patients with TS who had been treated and followed-up during childhood in the University Clinic for Pediatrics and Adolescent Medicine Vienna, Austria, from 1979 until 2011. We recruited our participants by contacting their families by mail at the last known address and sent a short questionnaire focusing on basic psychosocial status. The letter, together with the questionnaire, asked our former patients for an opinion on their current medical care. At the same time, they were invited to our department for further investigations. When no response was received within 5 weeks, we initiated a second contact, or eventually identified the current address using the national population registry. If both contact attempts were unsuccessful, we considered the recruitment unsuccessful (Fig. 1).

All participants have been informed per mail about the results of the tests, together with personalized medical recommendations, where needed. In addition, we offered the participants the chance to personally discuss the findings and to fill in another questionnaire regarding

$$
\begin{aligned}
& \text { http://www.endocrineconnections.org } \\
& \text { https://doi.org/10.1530/EC-18-0053 } 2018 \text { The authors }
\end{aligned}
$$

the preferred type of follow-up (general practitioner, specialized center or combination of the two). Only 20 participants positively responded to our invitation and filled in the questionnaire.

Information from childhood care (growth hormone therapy duration, age at diagnosis, pubertal development and diagnosed pathologies) was collected using patient files still available at our department. Age at transfer to adult medical follow-up was 18 years.

\section{Auxology and examinations}

During the visit, patients underwent a structured personal interview, physical examination (height, weight, blood pressure measurement), routine blood analysis, cardiac ultrasound and bone mineral density measurement using dual energy X-ray absorptiometry (DEXA), following recommendations available at that time (5). For analyzing the DEXA results, we corrected the T-scores for height, as it is known that bone mineral density is lower in shortstatured individuals (22). Height was measured using a Harpenden stadiometer and expressed in standard deviation scores (SDS), compared to Austrian height data (23). Hypertension was diagnosed according to the World Health Organization's criteria and defined as systolic values over $140 \mathrm{mmHg}$ and diastolic over $90 \mathrm{mmHg}$ after repeated measurements. Participants also underwent a 24-h blood pressure measurement for confirming the diagnosis. Data for BMI, patients' education and marital status were related to frequencies in the Austrian population, as reported by the 'Statistik Austria', the national statistical office.

\section{Quality of life}

The QoL assessment was done using the standardized German version of SF-36, version 2 Health Survey Quality of life Assessment Package (SF-36v2) (24). Physical and mental health areas were investigated using eight scales: primary (General Health, Vitality, Role Emotional, Social Functioning) and secondary (Physical Functioning, Role Physical, Bodily Pain and Mental Health) compared to the SF-36v2 reference population. Results were documented on a scale from 0 to 100 , where higher scores show a better quality of life.

\section{Depression assessment}

Depression was evaluated using the summary score of Beck's Depression Inventory Version II (BDI-II) (25). The standardized cut-offs are 0-13 points: minimal depression,

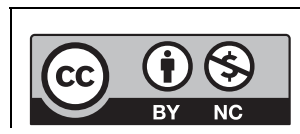

This work is licensed under a Creative Commons Attribution-NonCommercial 4.0 International License. 


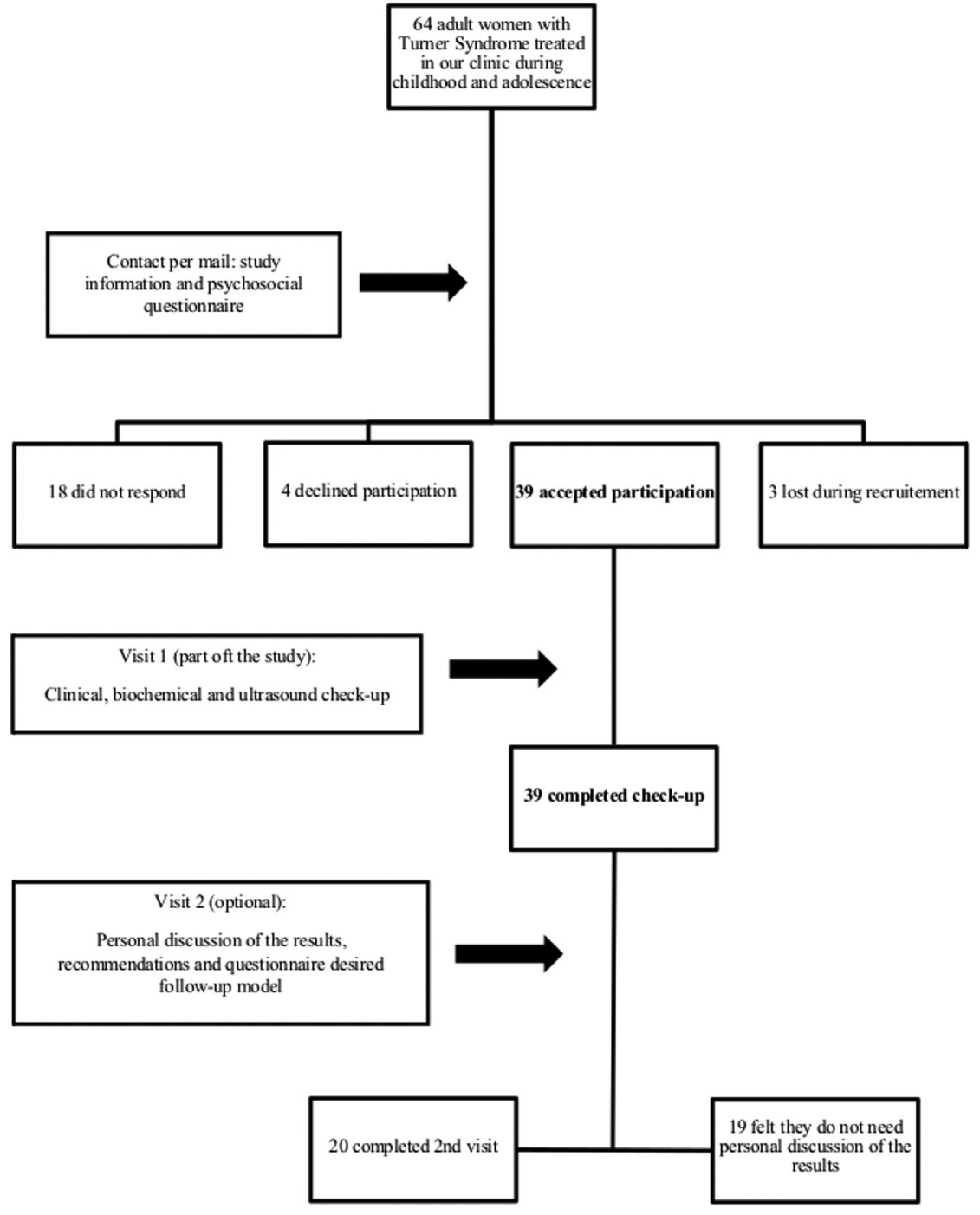

Figure 1

Recruitment and study process.
14-19 points: mild depression, 20-28 points: moderate depression and 29-63 points: severe depression.

The structured interview consisted of questions regarding current health issues (general, endocrine, cardiac, renal, skeletal, hearing impairment), social status (sexual relationships, marriage, employment and education), current medical care (by general practitioner, specialists and/or specialized clinic) and current therapies (after transition), with a special focus on estrogen therapy.

\section{Self-estimated medical status}

Participants were asked to rate (adequate vs inadequate) their current medical health care and the way they perceive their actual estrogen status based on their experiences with sexual life, libido and the occurrence of menstrual bleeding. After consulting with our study partner from

\begin{tabular}{lr}
\hline http://www.endocrineconnections.org & $\odot 2018$ The authors \\
https://doi.org/10.1530/EC-18-0053 & Published by Bioscientifica Ltd
\end{tabular}

the Department of Gynecology, we have decided to use the serum levels of $60 \mathrm{pg} / \mathrm{mL}$ as cut-off for an adequate substitution, together with the kind of prescription used (data not shown); if the patient was using a medication, which contained the right dose of estrogen, but also a gestagen and had a serum value above $60 \mathrm{pg} / \mathrm{mL}$, the substitution was considered adequate.

The objective quality of medical care was rated by whether or not the published recommendations (5) have been followed by the clinicians involved (e.g. yearly standard blood analysis, measurement of blood pressure, and every 3-5 years echocardiography, densitometry, hearing test, screening for coeliac disease and autoimmune thyroiditis). When at least one of these recommended procedures has not been performed since transfer into adult medical care, we were classifying the medical care as inadequate.

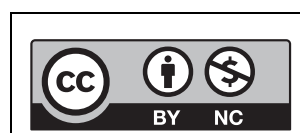

This work is licensed under a Creative Commons Attribution-NonCommercial 4.0 International License. 
The study was approved by the Local Ethical Committee of the Medical University of Vienna. Informed consent was signed by all participants.

\section{Statistics}

The distributions of categorical variables are described with counts and percentages. The percentage for QoL parameters are presented with asymptotic $95 \%$ confidence interval. Continuous variables are described with medians and quartiles or range due to the non-symmetric distribution of most variables and graphically presented as boxplots. The association of non-normally distributed continuous variables was quantified using Spearman correlation coefficients. Calculations were performed using SPSS, version 20 and SAS, version 9.4. $P$ values $\leq 0.05$ were considered statistically significant and were not corrected for multiple testing due to the exploratory character of this study.

\section{Results}

The population demographics are shown in Table 1 . The age of our 39 participants ranged between 21 and 43 years and the final height between -6.5 and -0.9 SDS (median: -3.5), compared with Austrian reference data (23). Only 3 participants had experienced spontaneous puberty. 32/39 women were receiving growth hormone therapy during childhood and adolescence.

BMI incidence in our group is shown in Table 2, together with the BMI distribution in the Austrian population as reported by 'Statistik Austria'. Two participants suffered from 3rd degree obesity.

\section{Socio-demographic data}

Data regarding education status from 38 women with TS were compared to the reported frequencies in the agematched Austrian general population, as provided by

Table 1 Study population: demographics.

\begin{tabular}{|c|c|}
\hline & Median (min-max) \\
\hline Age at diagnosis (years) & $10.6(0.1-17.5)$ \\
\hline Age at GH-therapy (years) & $9.9(3.9-16.5)$ \\
\hline Duration of GH-therapy (months) & $48.5(7-143)$ \\
\hline Final height (SDS*) & $-3.5((-6.5)$ to $(-0.94))$ \\
\hline $\mathrm{BMI}^{* *}$ at transfer & $21.5(14.1-33.8)$ \\
\hline $\begin{array}{l}\text { Time spent in adult follow-up } \\
\text { (years) }\end{array}$ & $17(3-25)$ \\
\hline Age at study recruitment & $35(21-43)$ \\
\hline
\end{tabular}

*Standard deviation score; **body mass index.

$$
\text { http://www.endocrineconnections.org }
$$

'Statistik Austria': compulsory education 14/38 (36.8\%) in the study group vs $11.3 \%$ in the general population, highschool $13 / 38(34.2 \%)$ vs $66.7 \%$ and university education $11 / 38(28.9 \%)$ vs $21.9 \%$ respectively.

The majority of women with TS lived as singles (27/39, 69.2\%); distinctly fewer were married compared with the Austrian reference of the same age: $6 / 39$ (15.4\%) married and 6/39 (15.8\%) in a relationship vs $35.4 \%$ in the Austrian population; however, 'Statistik Austria' data do not distinguish between 'single' and 'in a relationship', but only give information about marriage.

\section{Current medical care}

Based on the answers provided in the baseline questionnaire, we have found that $7 / 39$ of our former patients have not visited any doctor since transfer to adult medical care. 24/39 were in regular follow-up by a gynecologist and 6 were seen in a specialized gynecological setting (university clinic). $33 / 39$ of the patients had not been seen by a cardiologist since transfer to adult medical care, and only 2 had been seen in a specialized cardiology center.

We could not detect correlation coefficients above an absolute value of 0.50 between our classification of sufficient/insufficient quality of current medical care and the variables of relationship status, level of education, eventual spontaneous puberty or adult height (Supplementary Table 2, see section on supplementary data given at the end of this article).

\section{Relevant diagnosed comorbidities}

The diagnoses made in the course of individual patients' history are shown in Table 3. In total, 27 out of 39 women had one or more newly diagnosed disease (right column). Besides these diagnoses given in Table 3, two women were diagnosed with hearing impairment, one with glaucoma and two had psoriasis. At the time of discharge from pediatric care, none of the patients had hypothyroidism (subclinical or manifest). Nine were diagnosed after this point with hypothyroidism and received treatment; during this study, three other participants were diagnosed and L-thyroxin was started. In total, 19/39 had positive thyroid antibodies at the time of the study.

Two women were diagnosed with thyroid carcinomas after transition during routine thyroid diagnostics including ultrasound. One presented with papillary thyroid carcinoma (pT2a pN1 M0), the other with angioinvasive, follicular thyroid carcinoma (pT2 NO Mo). Both were undergoing thyroidectomy and radiotherapy.

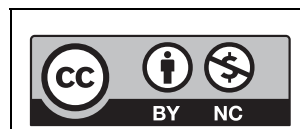

This work is licensed under a Creative Commons Attribution-NonCommercial 4.0 International License. 
Table 2 Body mass index distribution in the study group and in the Austrian general population.

\begin{tabular}{l} 
Age groups \\
$15-30$ years \\
30-45 years \\
\hline
\end{tabular}

\begin{tabular}{ccc}
\hline \multicolumn{3}{c}{ BMI study population $(n /$ total $(\%))$} \\
\hline$<25$ & $25-30$ & $>30$ \\
$6 / 12(50)$ & $2 / 12(17)$ & $4 / 12(33)$ \\
$10 / 27(37)$ & $9 / 27(33)$ & $8 / 27(30)$ \\
\hline
\end{tabular}

\begin{tabular}{ccc}
\hline \multicolumn{3}{c}{ BMI Austrian population* $(\%)$} \\
\hline$<25$ & $25-30$ & $>30$ \\
63.6 & 12.8 & 5.7 \\
65 & 21.1 & 9.1 \\
\hline
\end{tabular}

*Statistik Austria 2014/2015

\section{Subjective and objective evaluation of current medial health care}

When asked about the sufficiency of their current medical health care, 25/39 of the participants thought they were being adequately treated. In contrast to the subjective perception of the patients, the objective evaluation showed that only 3 currently had adequate medical health care, while 36 were being inadequately treated (Table 4 ).

\section{Estrogen substitution}

Out of 39 women, 31 were currently taking estrogen substitution, while 7 were not taking any ( 1 missing data). When asked to rate the perception of their actual estrogen status, 25 thought it was adequate and 14 considered it inadequate (Table 4).

Serum estrogen levels showed a statistically significant difference between the participants' subjective perceptions of their estrogen levels and the medical necessity for a higher level of substitution: while 17 participants were receiving adequate substitution, 5 had estrogen levels, which were considered low. All the women who were receiving adequate substitution were taking an estrogengestagen supplementation in accordance with recent recommendations (5).

Despite the overall insufficient status of estrogen substitution, densitometry was normal after correction for height in all participants, with a mean $\mathrm{T}$ score lumbar spine of -0.76 SDS and a range from -3 to 2.1 SDS. None of the women had experienced fractures.

\section{Quality of life analysis (SF36v2)}

QoL data for the 8 sub-scales are presented in Fig. 2 and Supplementary Table 1. 38 out of 39 participants completed the questionnaire. Women with TS in our study showed higher percentages of scores above 55 compared with the SF-36V2 reference population in almost all of the 8 sub-scales (expected proportion: $31 \%$ ).

Table 3 Diagnosed comorbidities - summary for the 39 participants.

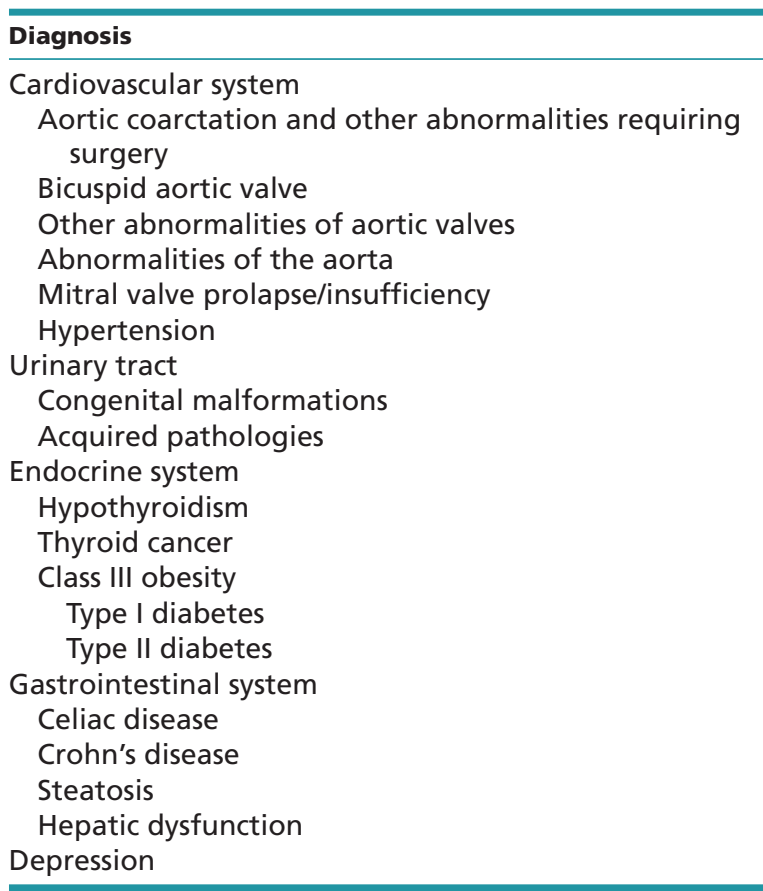

Cardiovascular system

Aortic coarctation and other abnormalities requiring

Other abnormalities of aortic valves

Mitral valve prolapse/insufficiency

Hypertension

Congenital malformations

Acquired pathologies

Class III obesity

Type I diabetes

Celiac disease

Crohn's diseas

Hepatic dysfunction

Depression

\begin{tabular}{|c|}
\hline At the time of transition $(n)$ \\
\hline 6 \\
\hline 3 \\
\hline 3 \\
\hline- \\
\hline- \\
\hline 4 \\
\hline 14 \\
\hline- \\
\hline- \\
\hline- \\
\hline- \\
\hline - \\
\hline- \\
\hline 1 \\
\hline- \\
\hline- \\
\hline- \\
\hline- \\
\hline
\end{tabular}

After transition $(n)$

During the study $(n)$ 
Table 4 Estrogen and current medical care status: subjective vs objective estimation.

\begin{tabular}{lccc}
\hline & & Adequate $(n /$ total) & Inadequate $(n /$ total) \\
\cline { 1 - 1 } $\begin{array}{lcc}\text { Estrogen status } \\
\text { Subjective }\end{array}$ & $27 / 39$ & $12 / 39$ \\
Objective & $21 / 39$ & $18 / 39$ \\
Actual medical care & & \\
Subjective & $25 / 39$ & $14 / 39$ \\
Objective & $3 / 39$ & $36 / 39$ \\
\hline
\end{tabular}

Figure 3 shows the distribution of the data for all 8 sections of the QoL SF-36v2 compared to the reference population and pointing to a tendency towards patients with TS scoring better than average in the physical scales. Our study sample was slightly more susceptible for depression than women from the general population (23.7\% (95\% CI: 13.4-41.9) for the Turner sample vs $18 \%$ for the SF-36v2 reference population).

The following correlations between the categories 'quality of estrogen substitution', 'educational status' and sub-scores of the SF36v2 were weak, however, interesting: current estrogen substitution based on objective evaluation had a weak negative correlation with bodily pain $(r=-0.39$, uncorrelated $P=0.015)$ and general health $(r=-0.36$, uncorrelated $P=0.025)$, which might indicate that a suboptimal hormonal substitution could have interfered with feeling healthy; in these 2 sections, participants with suboptimal substitution had lower scores than the those who were being optimally treated.

Adult height in SDS correlated weakly positively with the physical component $(r=-0.39$, uncorrelated $P=0.015)$.

BMI showed a weak negative correlation with the physical component, where participants who were obese presented with lower scores in this section, but not lower as the SF36v2 reference population. Furthermore, we could see a stronger positive correlation between the level of education, the section 'role physical functioning' ( $r=0.46$, uncorrelated $P=0.005$ ) and also the 'physical component summary' ( $r=0.49$, uncorrelated $P=0.002)$, suggesting that women with TS with a higher education encounter fewer limitations regarding physical functioning in daily life. The most important correlation data are presented in Supplementary Table 2. Karyotype had no effect on the QoL physical health score. Furthermore, there was no statistically significant effect of the mode of medical follow-up or current medical care.

\section{Beck's depression inventory}

36 from 39 participants completed the Beck's depression inventory. Three women with scores suggesting mild depression had extremely low adult height $(-4.16,-4.35$ and -5.96 SDS, despite growth hormone therapy during childhood), but were heterogeneous for their level of education. One woman presented with severe depression. Adult height did not affect the BDI-II scores of any patients in the group. Karyotype, spontaneous puberty, medical follow-up, current medical care, family status, BMI and level of education on depression scores also had not effect. However, BDI-II scores correlated slightly with the patients' subjective evaluations of their current estrogen substitution with a Spearman correlation coefficient of 0.390 and $P$ value of 0.027 .

\section{Patients' views of the optimal model of adult medical care}

After their visit, we sent patients a final questionnaire on their wishes for their future medical health care. They were asked what kind of model of care they would feel
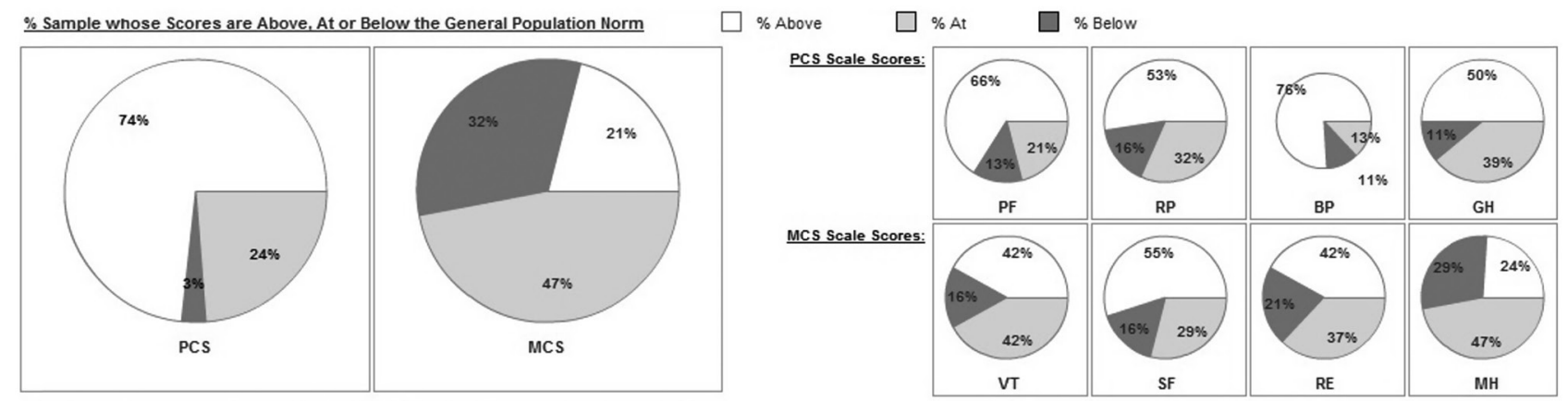

Note: This report utilizes normative dats from the QualityMetric 2009 General Population Sample. Note: Totals may not equal $100 \%$, due to statistical rounding.

\section{Figure 2}

QoL scoring in percentages 'at the general population norm' (within 45 and 55, i.e. mean $\pm 1 / 2$ S.D. of the SF-36V2 reference population), 'above the general population' (above 55 , i.e. above mean $+1 / 2$ S.D.) and 'below the general population' (below 45 , i.e. below mean $-1 / 2$ S.D.).

http://www.endocrineconnections.org https://doi.org/10.1530/EC-18-0053
(C) 2018 The authors Published by Bioscientifica Ltd

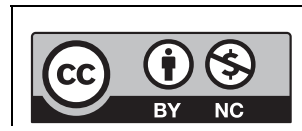

This work is licensed under a Creative Commons Attribution-NonCommercial 4.0 International License. 


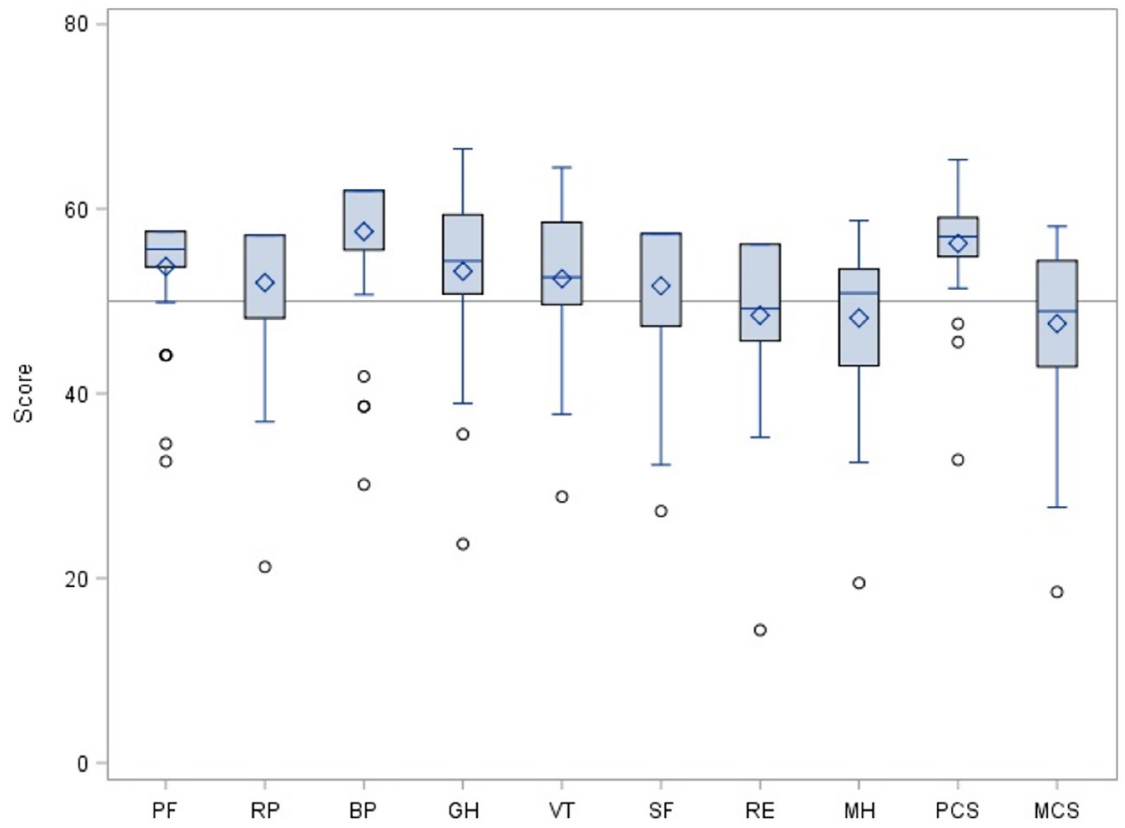

Figure 3

Boxplots showing QoL data distribution for al the 8 sections of the domains analyzed. PCS, physical component summary; MCS, mental component summary; PF, physical functioning; RP, role physical; $\mathrm{BP}$, bodily pain; $\mathrm{GH}$, general health; VT, vitality; SF, social functioning; RE, role emotional; $\mathrm{MH}$, mental health. Horizontal lines refer to mean (50) and mean $\pm 1 / 2$ S.D. (45 and 55 , respectively) of the SF-36V2 reference population. comfortable with. The questionnaire was completed by 20 patients. 14 participants found a combined medical follow-up, with visits at the general practitioner and at the specialists, as efficient; still 15 participants would be rather interested in follow-ups, which take place in a specialized clinic.

$14 / 20$ participants said they considered psychological support during future visits would not be useful.

\section{Discussion}

Studies on aspects of the quality of life and general health status of patients with Turner syndrome over the last 30 years have had different aims and looked at various questions.

Besides judging the success of the therapy by increased centimeters in adult height, early studies on psychosocial and general health aspects in TS addressed the impact of height and of height increase on physical and mental wellbeing. These studies all reported about normal QoL scores $(26,27,28)$, with no influence of growth hormone therapy or adult height. The present study is not able to add new information as to whether or not growth hormone therapy during childhood improves QoL in later life in women with TS because nearly all of our patients had been treated with growth hormone and we did not include a control group. However, when analyzing subscales of the SF-36v2 questionnaire in relation to adult height, we found a weak correlation with the physical health component summary (PCS), indicating shorter women felt some physical impairment.

Previous studies investigating middle-aged women with TS concentrated on the health and marital status or educational aspects and their impact on quality of life rather than the effect of growth hormone therapy during childhood. Two studies on health status and confounding factors firstly reported women with TS at a mean age of 34 years scoring statistically significantly lower on the two subscales 'physical functioning' and 'general health' (29), and in a follow-up study 6 years later found participants had higher frequencies of health disorders, lower self-esteem, higher stress rates and overall faced more challenges on several domains of physical and social functioning (30).

In our study, adult height was not associated with subscales of mental health or with the BDI-II depression score nor did it correlate with the level of education. However, we found a weak correlation of educational level with QoL, with women of higher education scoring better.

Importantly, we found a high percentage of newly diagnosed comorbidities in women with TS after transition. Most participants were convinced they were receiving optimal medical care, whereas only a few were receiving the recommended follow-up. The diagnosis of thyroid carcinoma in 2 out of 39 participants, both under 30 years of age, is surprising, as a risk for malignancy had not previously been reported in women with TS (1). Nevertheless, a link between autoimmune thyroiditis and papillary thyroid cancer (PTC) has been known for years (31), although the pathogenesis is unclear. Likewise,

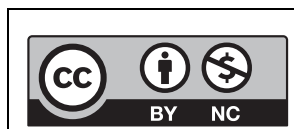

This work is licensed under a Creative Commons Attribution-NonCommercial 4.0 International License. 
growth hormone therapy might increase the thyroid cancer risk (32), while hypothyroidism and autoimmune thyroiditis predispose to more frequent neck ultrasounds (ascertainment bias), leading to a higher detection rate of dormant microcarcinomas (33). Nevertheless, our TS population might constitute a population at risk.

The observation that our participants presented with good QoL scores and reported their current medical health and follow-up as adequate is in sharp contrast to the objective findings of newly diagnosed comorbidities and the suboptimal prescription of estrogen therapy. Different reasons could explain this discrepancy. Women with TS could be underestimating the complexity of their own health status (34) and need for medical care and thus be escaping established screening for comorbidities or they could have strong coping mechanisms (30). Women with TS have been reported to cope well with other issues likely to generate a burden in daily life, although they are at higher risk for low self-esteem, less satisfaction with vocational life or romantic love (35). Surprisingly, 14 of the 20 interviewed women did not feel the need for incorporating psychological support into their regular medical visits, which contrasts with findings in other studies (21). Regardless of whether good coping mechanisms or underestimation of the disease is the explanation, in view of the conflicting study findings, more studies are required to clarify these aspects.

Only $4 \%$ of adult women with TS undergo the recommended health care investigations on a preventive and regular basis $(2,13)$. Besides reasons such as institutional and/or health systems lacking appropriate infrastructure, the complex clinical picture in TS, with possible involvement of more than one organ system, complicates this process. 'Transition' in our center has been beset with the same difficulties as in many other centers. Our participants were from a generation who all had been offered growth hormone therapy during childhood and who had been closely followed up by a pediatric endocrinologist until the age of 18 years in most cases. At that time, we had no established formal transition and/or transfer process at our institution; patients were given their final medical reports and recommendations for further medical follow-up at the gynecological or internal medicine department. Only adolescents with congenital cardiac abnormalities were referred to an adult clinic specialized in cardiology. Realizing how insufficient this earlier transition process had been, we were prompted to contact all our previous patients to inform them about current standards of health care in TS and invite them to participate in the study including a complete health-check.
Ourstudy results showed that most women with TS want to be treated at a tertiary center. In our opinion, until such specialized centers with multidisciplinary teams become a reality, we have to individualize medical care for groups of patients with rare diseases as far as institutional resources allow. We propose a 'longitudinal multidisciplinary model' of medical care. The pediatric endocrinologist in conjunction with a gynecologist should optimally prepare patients for the transfer, by encouraging patient's health autonomy (17) and by providing insightful information about estrogen therapy and fertility issues. In this model, the endocrine gynecologist in close collaboration with the adult endocrinologist would coordinate follow-up during young adulthood. The optimal frequency of cardiologic follow-up also needs to be established for each individual patient at the time of transition by a pediatric cardiologist on the basis of current recommendations (9). We believe each tertiary center needs to define the optimal multidisciplinary model of medical care appropriate for its location as health systems differ between countries.

We are aware of the weaknesses of our study, such as the inevitable low number of patients due to the rare nature of the disease and lack of an age-matched control group, but we consider our results nevertheless indicate the need for further multicenter studies to assess transition of patients with TS and the health care they receive during adulthood. We did indeed use the SF-36v2 reference population for our QoL assessment, but data in the literature have shown minimal differences when compared to the German population (36).

The main strength of this study is that we have seen all participants personally and have discussed the questionnaires with each one of them. We actively investigated every patient's current health status and interpreted the results objectively, using the recommendations provided in the literature. New diagnosed comorbidities and treatment recommendations (L-Thyroxin, Vitamin D supplementation) were communicated personally during a second visit, in which we also offered immediate support for participants with more severe symptoms.

\section{Supplementary data}

This is linked to the online version of the paper at https://doi.org/10.1530/ EC-18-0053.

\section{Declaration of interest}

The authors declare that there is no conflict of interest that could be perceived as prejudicing the impartiality of the research reported.

\section{This work is licensed under a Creative Commons} Attribution-NonCommercial 4.0 International License. 


\section{Funding}

This work was supported in part by a research grant from the "Medical Scientific Fund of the Mayor of the City of Vienna" and by an investigatorinitiated Pfizer research grant.

\section{References}

1 Stochholm K, Juul S, Juel K, Naeraa RW \& Gravholt CH. Prevalence, incidence, diagnostic delay, and mortality in Turner syndrome. Journal of Clinical Endocrinology and Metabolism 200691 3897-3902. (https://doi.org/10.1210/jc.2006-0558)

2 Gawlik A \& Malecka-Tendera E. Transition in: treatment of Turner's syndrome during transition. European Journal of Endocrinology 2014 170 57-74. (https://doi.org/10.1530/EJE-13-0900)

3 Pinsker JE. Turner syndrome: updating the paradigm of clinical care. Journal of Clinical Endocrinology and Metabolism 201297 994-1003. (https://doi.org/10.1210/jc.2012-1245)

4 Davenport ML. Approach to the patient with Turner syndrome. Journal of Clinical Endocrinology and Metabolism 201095 1487-1495. (https://doi.org/10.1210/jc.2009-0926)

5 Bondy CA. Care of girls and women with Turner syndrome: a guideline of the Turner syndrome study group. Journal of Clinical Endocrinology and Metabolism 200792 10-25. (https://doi. org/10.1210/jc.2006-1374)

6 Donaldson MDC. Optimizing management in Turner syndrome: from infancy to adult transfer. Archives of Disease in Childhood 2006 91 513-520. (https://doi.org/10.1136/adc.2003.035907)

7 Saenger P, Wikland KA, Conway GS, Davenport M, Gravholt CH, Hintz R, Hovatta O, Hultcrantz M, Landin-Wilhelmsen K, Lin A, et al. Recommendations for the diagnosis and management of Turner syndrome. Journal of Clinical Endocrinology and Metabolism 200186 3061-3069. (https://doi.org/10.1210/jcem.86.7.7683)

8 Gravholt CH, Andersen NH, Conway GS, Dekkers OM, Geffner ME, Klein KO, Lin AE, Mauras N, Quigley CA, Rubin K, et al. Clinical Practice Guidelines for the care of girls and women with Turner syndrome: proceedings from the 2016 Cincinnati International Turner Syndrome Meeting; International Turner Syndrome Consensus Group. European Journal of Endocrinology 2017177 G1-G70. (https://doi.org/10.1530/EJE-17-0430)

9 Turtle EJ, Sule AA, Webb DJ \& Bath LE. Aortic dissection in children and adolescents with Turner syndrome: risk factors and management recommendations: Table 1. Archives of Disease in Childhood 2015100 662-666. (https://doi.org/10.1136/archdischild-2014-307080)

10 Mortensen KH, Hjerrild BE, Stochholm K, Andersen NH, Sørensen KE, Lundorf E, Hørlyck A, Pedersen EM, Christiansen JS \& Gravholt $\mathrm{CH}$. Dilation of the ascending aorta in Turner syndrome - a prospective cardiovascular magnetic resonance study. Journal of Cardiovascular Magnetic Resonance 201113 24. (https://doi. org/10.1186/1532-429X-13-24)

11 Gawlik A, Kaczor B, Kaminska H, Zachurzok-Buczynska A, Gawlik T \& Malecka-Tendera E. Quality of medical follow-up of young women with Turner syndrome treated in one clinical center. Hormone Research in Paediatrics 201277 222-228. (https://doi. org/10.1159/000337780)

12 Freriks K, Timmermans J, Beerendonk CCM, Verhaak CM, NeteaMaier RT, Otten BJ, Braat DD, Smeets DF, Kunst DH, Hermus AR, et al. Standardized multidisciplinary evaluation yields significant previously undiagnosed morbidity in adult women with Turner syndrome. Journal of Clinical Endocrinology and Metabolism 201196 1517-1526. (https://doi.org/10.1210/jc.2011-0346)

13 Devernay M, Ecosse E, Coste J \& Carel J-C. Determinants of medical care for young women with Turner syndrome. Journal of Clinical Endocrinology and Metabolism 200994 3408-3413. (https://doi. org/10.1210/jc.2009-0495)
14 Verlinde F, Massa G, Lagrou K, Froidecoeur C, Bourguignon JP, Craen M, De Schepper J, Du Caju M, Heinrichs C, François I, et al. Health and psychosocial status of patients with Turner syndrome after transition to adulthood: the Belgian experience. Hormone Research in Paediatrics 200462 161-167. (https://doi. org/10.1159/000080099)

15 Gleeson H \& Turner G. Transition to adult services. Archives of Disease in Childhood: Education and Practice Edition 201297 86-92. (https:// doi.org/10.1136/archdischild-2011-300261)

16 Davies MC. Lost in transition: the needs of adolescents with Turner syndrome. British Journal of Obstetrics and Gynaecology 2010117 134-136. (https://doi.org/10.1111/j.1471-0528.2009.02410.x)

17 Culen C, Ertl DA, Schubert K, Bartha-Doering L \& Haeusler G. Care of girls and women with Turner syndrome: beyond growth and hormones. Endocrine Connections 20176 R39-R51. (https://doi. org/10.1530/EC-17-0036)

18 Boman UW, Bryman I \& Möller A. Psychological well-being in women with Turner syndrome: somatic and social correlates. Journal of Psychosomatic Obstetrics and Gynaecology 200425 211-219.

19 Boman UW, Bryman I, Halling K \& Möller A. Women with Turner syndrome: psychological well-being, self-rated health and social life. Journal of Psychosomatic Obstetrics and Gynaecology 200122 113-122. (https://doi.org/10.3109/01674820109049961)

20 Dörholt D, Noeker M, Ranke MB \& Haverkamp F. Body height, body image and general well-being in adult women with Turner's syndrome. In Growth, Stature and Psychological Well-Being, pp 95-103. Eds U Eiholzer, F Haverkamp \& LD Voss. Seattle, WA, USA: Hogrefe \& Huber, 1999.

21 Pavlidis K, McCauley E \& Sybert VP. Psychosocial and sexual functioning in women with Turner syndrome. Clinical Genetics 1995 47 85-89. (https://doi.org/10.1111/j.1399-0004.1995.tb03929.x)

22 Nordin BEC. Reflections on osteoporosis. In Osteoporosis, 4th ed., vol. 1, pp 31-50. Oxford, UK: Academic Press, 2013. (https://doi. org/10.1016/B978-0-12-415853-5.00003-0)

23 Gleiss A, Lassi M, Blümel P, Borkenstein M, Kapelari K, Mayer M, Schemper M \& Häusler G. Austrian height and body proportion references for children aged 4 to under 19 years. Annals of Human Biology 201340 324-332. (https://doi.org/10.3109/03014460.2013.77 6110)

24 Ware JE, Kosinski M, Bjorner JB, Turner-Bowker DM, Gandek B \& Maruish ME. 2007 User's Manual for the SF-36v2 Health Survey, 2nd ed. Lincoln, RI, USA: Quality Metric Incorporated, 2007.

25 Beck AT, Steer RA \& Brown GK. Manual for the Beck Depression Inventory-II. San Antonio, TX, USA: Psychological Corporation, 1996.

26 Taback SP \& Van Vliet G. Health-related quality of life of young adults with Turner syndrome following a long-term randomized controlled trial of recombinant human growth hormone. BMC Pediatrics 201111 49. (https://doi.org/10.1186/1471-2431-11-49)

27 Bannink EM, Raat H, Mulder PG \& de Muinck Keizer-Schrama SM. Quality of life after growth hormone therapy and induced puberty in women with Turner syndrome. Journal of Pediatrics 2006148 95-101. (https://doi.org/10.1016/j.jpeds.2005.08.043)

28 Carel JC, Ecosse E, Bastie-Sigeac I, Cabrol S, Tauber M, Léger J, Nicolino M, Brauner R, Chaussain JL \& Coste J. Quality of life determinants in young women with Turner's syndrome after growth hormone treatment: results of the StaTur population-based cohort study. Journal of Clinical Endocrinology and Metabolism 200590 1992-1997. (https://doi.org/10.1210/jc.2004-1395)

29 Naess EE, Bahr D \& Gravholt CH. Health status in women with Turner syndrome: a questionnaire study on health status, education, work participation and aspects of sexual functioning. Clinical Endocrinology 201072 678-684. (https://doi.org/10.1111/j.13652265.2009.03715.x)

30 Fjermestad KW, Naess EE, Bahr D \& Gravholt CH. A 6-year follow-up survey of health status in middle-aged women with Turner

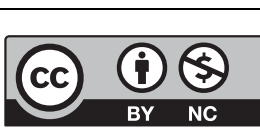


syndrome. Clinical Endocrinology 201685 423-429. (https://doi. org/10.1111/cen.13068)

31 Noureldine SI \& Tufano RP. Association of Hashimoto's thyroiditis and thyroid cancer. Current Opinion in Oncology 201427 21-25. (https://doi.org/10.1097/CCO.0000000000000150)

32 Cabanas P, García-Caballero T, Barreiro J, Castro-Feijóo L, Gallego R, Arévalo T, Cañete R \& Pombo M. Papillary thyroid carcinoma after recombinant GH therapy for Turner syndrome. European Journal of Endocrinology 2005153 499-502. (https://doi.org/10.1530/ eje.1.01988)

33 Brito JP, Morris JC \& Montori VM. Thyroid cancer: zealous imaging has increased detection and treatment of low risk tumours. BMJ 2013 347 f4706. (https://doi.org/10.1136/bmj.f4706)
34 Stalla GK, Athanasoulia AP, Führer D, Frank-Herrmann P, Oppelt PG, Hauffa BP \& Dörr HG. Transition of young women with Turner syndrome to adult medicine. Current recommendations of an expert workshop. Monatsschrift Kinderheilkunde 2013161 1180-1186. (https://doi.org/10.1007/s00112-013-3016-2)

35 Kagan-Krieger S. Factors that affect coping with Turner syndrome. Journal of Nursing Scholarship 200133 43-45. (https://doi. org/10.1111/j.1547-5069.2001.00043.x)

36 Ellert U \& Kurth BM. Health related quality of life in adults in Germany. Results of the German Health Interview and Examination Survey for Adults (DEGS1). Bundesgesundheitsblatt, Gesundheitsforschung, Gesundheitsschutz 201356 643-649. (https:// doi.org/10.1007/s00103-013-1700-y)

Received in final form 1 March 2018

Accepted 7 March 2018

Accepted Preprint published online 7 March 2018 http://www.endocrineconnections.org https://doi.org/10.1530/EC-18-0053
(C) 2018 The authors Published by Bioscientifica Ltd

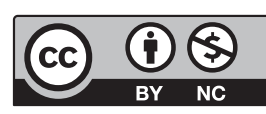

This work is licensed under a Creative Commons Attribution-NonCommercial 4.0 International License. 